\title{
Evaluation of nitrogen status in a wheat crop using unmanned aerial vehicle images
}

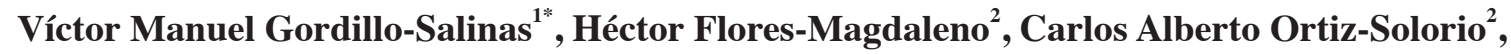 \\ and Ramón Arteaga-Ramírez ${ }^{3}$
}

\begin{abstract}
${ }^{1}$ Instituto Mexicano de Tecnología del Agua, Coordinación de Riego y Drenaje, Paseo Cuauhnáhuac No. 8532, Jiutepec, Morelos 62550, México. "Corresponding author (manuel_gordillo@tlaloc.imta.mx).

${ }^{2}$ Colegio de Postgraduados, Campus Montecillo, Carretera México-Texcoco, km 36.5 Montecillo, Texcoco 56230, México.

${ }^{3}$ Universidad Autónoma Chapingo, Departamento de Irrigación, km 38.5 Carr. México-Texcoco, Chapingo, Texcoco 56230, México.
\end{abstract}

Received: 27 January 2021; Accepted: 14 April 2021; doi:10.4067/S0718-58392021000300408

\begin{abstract}
The excessive use of $\mathrm{N}$ in agriculture has created various environmental and economic problems. Remote sensing and unmanned aerial vehicles (UAV) are feasible solutions to infer the status of a crop and enable a better management during the growing season. The objective of this study was to correlate experimental $\mathrm{N}$ content and wheat (Triticum aestivum L.) crop aboveground biomass data with vegetation indices estimated using UAV images. In this study, the N nutrition index and $\mathrm{N}$ dilution curve were used as indicators of the state of plant $\mathrm{N}$; input variables to estimate these indicators were the $\mathrm{N}$ content and aboveground biomass. Four flight campaigns were conducted at different phenological stages of a wheat crop and seven $\mathrm{N}$ doses were evaluated. A linear relationship of blue normalized difference vegetation index (BNDVI) and green normalized difference vegetation index (GNDVI) with aboveground biomass and N content was identified. BNDVI and biomass demonstrated high $\mathrm{R}^{2}$ during boots swollen and end of anthesis growth stages $(0.62$ and 0.68 , respectively), while GNDVI showed the highest $\mathrm{R}^{2}$ during the ear half emerged and beginning of anthesis growth stages ( 0.84 and 0.79 , respectively). For $\mathrm{N}$ content estimation, GNDVI showed a higher correlation than BNDVI, and the adjustment curve showed an $\mathrm{R}^{2}$ up to 0.81 only for the last flight (end of anthesis), BNDVI showed an $\mathrm{R}^{2}$ of 0.78 . Remote sensing and vegetation indices estimated from UAV images can be reliably used to estimate $\mathrm{N}$ content and wheat biomass, contributing to knowing the crop $\mathrm{N}$ status.
\end{abstract}

Key words: Blue normalized difference vegetation index, critical nitrogen dilution curve, green normalized difference vegetation index, nitrogen nutrition index, Triticum aestivum.

\section{INTRODUCTION}

Intensive agriculture has forced a paradigm shift in the efficient management of fertilization. The dilemma is continually producing higher volumes of agricultural products to meet human, livestock, and industrial demands while efficiently using natural resources.

Within context of intensive agricultural production, the irrational and excessive application of chemical fertilizers is one of the main causes of pollution of different ecosystems. Specifically, N, one of plants' required macro elements, is often excessively applied, which has created a number of negative human and environmental impacts, like eutrophication, acid rain, drinking water pollution, and emissions of nitrous oxides (Spiertz, 2010; Cameron and Moir, 2013).

Farmers and agricultural managers are interested in measuring and evaluating the nutritional status of crops at specific critical times: in early growth stages to provide adequate amounts of fertilizers for normal crop growth, and during the advanced development stage for health monitoring and performance prediction. 
For some years, remote sensing has played an important role in providing information in time and space for precision agriculture due to its ability to measure biophysical parameters and detect spatio-temporal variability.

Vegetation indices (VIs) have been proposed as indirect methods of measuring biophysical variables of vegetation based on spectral data obtained by remote sensing. Actually, the miniaturization of multispectral, hyperspectral, and thermal sensors; advances in software, hardware, electronics, and mechatronics; and the introduction of positioning technologies have allowed these sensors to be mounted on unmanned aerial vehicles (UAVs), making them more popular and a viable tool for precision agriculture (PA).

Wang et al. (2007) analyzed the relationship between the leaf area index (LAI), as a fundamental structural parameter in the description of the status of the vegetable cover of rice cultivation, and seven vegetation indices using visible spectrum bands measured with a radiometer. They found that LAI and normalized difference vegetation index (NDVI) in the different bands in the visible (VNDVI) had coefficient of determination $\left(\mathrm{R}^{2}\right)$ values higher than 0.85 , the blue NDVI (BNDVI) and green NDVI (GNDVI) had R ${ }^{2}$ of 0.981, and BNDVI and NDVI had $\mathrm{R}^{2}$ of 0.987.

Hunt et al. (2010) employed a digital camera (digital FinePix S3 Pro UVIR camera, Fujifilm, New Jersey, USA) mounted on a UAV as a method for measuring LAI of wheat, finding that the GNDVI is strongly correlated with this biophysical variable, reporting an $\mathrm{R}^{2}$ of 0.85 for LAI less than 2.7 .

Geipel et al. (2016) developed a multispectral camera prototype for the estimation of aboveground biomass and $\mathrm{N}$ content in winter wheat designed for UAVs. The system captures multispectral images with which NDVI and the red-edge inflection point (REIP) were estimated, finding that the best results for estimation of aerial biomass were produced with the NDVI $\left(\mathrm{R}^{2}=0.72-0.85\right)$, whereas the $\mathrm{N}$ content is better estimated using REIP $\left(\mathrm{R}^{2}=0.59-0.89\right)$.

The objective of this research was to determine if it is possible to diagnose wheat (Triticum aestivum L.) N status through the use of UAV images. The approach requires estimation of aboveground biomass and $\mathrm{N}$ content, estimated from vegetation indices obtained from images of a modified commercial camera mounted on a UAV platform. The study contemplates the use of a critical $\mathrm{N}$ dilution curve and a $\mathrm{N}$ nutrition index to determine if the $\mathrm{N}$ content was optimal, in excess or in deficiency status. This approach can help to overcome the complications of localize spatially the wheat crop $\mathrm{N}$ status.

\section{MATERIALS AND METHODS}

The research was conducted at the facilities of the Postgraduate College's Montecillo Campus, located in Texcoco, México. We used a plot with wheat (Triticum aestivum L.) 'Nana F2007'. It is classified as a variety of early cycle, 85 to $134 \mathrm{~d}$ maturity in rainfed conditions It is classified as a variety of strong, extensible gluten and good bread volume. Sowing density was $100 \mathrm{~kg} \mathrm{ha}^{-1}$.

The experiment surface area was around $3000 \mathrm{~m}^{2}$, a drip irrigation system was installed, maintaining the soil at field capacity to avoid this variable affecting the behavior of the different doses of $\mathrm{N}$ applied.

The experimental design was randomized complete block design, with seven $\mathrm{N}$ application treatments $(0,4,6,8,10,14$, and $18 \mathrm{~g} \mathrm{~m}^{-2}$ ) and four replicates (28 experimental units). The size of each experimental unit was $10 \times 4.5 \mathrm{~m}$ (Figure 1).

The total amount of $\mathrm{N}$ applied was divided into two parts: $\mathrm{N}$ was first applied during planting and then during the Z31 stage (Zadoks growth scale is a 0-99 development scale), which corresponds to the beginning of stem elongation (first

Figure 1. Arrangement of the experimental design.

\begin{tabular}{|c|c|c|c|c|c|}
\hline & I & II & III & I V & \multirow{7}{*}{ 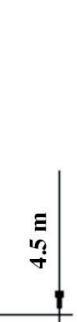 } \\
\hline \multirow{7}{*}{ 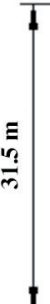 } & $0 \mathrm{gm}^{-2}$ & $10 \mathrm{~g} \mathrm{~m}^{-2}$ & $14 \mathrm{~g} \mathrm{~m}^{-2}$ & $4 \mathrm{~g} \mathrm{~m}^{-2}$ & \\
\hline & $14 \mathrm{~g} \mathrm{~m}^{-2}$ & $8 \mathrm{gm}^{-2}$ & $4 \mathrm{~g} \mathrm{~m}^{-2}$ & $10 \mathrm{~g} \mathrm{~m}^{-2}$ & \\
\hline & $10 \mathrm{~g} \mathrm{~m}^{-2}$ & $4 \mathrm{~g} \mathrm{~m}^{-2}$ & $18 \mathrm{~g} \mathrm{~m}^{-2}$ & $14 \mathrm{~g} \mathrm{~m}^{-2}$ & \\
\hline & $6 \mathrm{gm}^{-2}$ & $18 \mathrm{~g} \mathrm{~m}^{-2}$ & $6 \mathrm{gm}^{-2}$ & $0 \mathrm{~g} \mathrm{~m}^{-2}$ & \\
\hline & $8 \mathrm{gm}^{-2}$ & $6 \mathrm{gm}^{-2}$ & $10 \mathrm{~g} \mathrm{~m}^{-2}$ & $6 \mathrm{~g} \mathrm{~m}^{-2}$ & \\
\hline & $18 \mathrm{~g} \mathrm{~m}^{-2}$ & $0 \mathrm{gm}^{-2}$ & $8 \mathrm{gm}^{-2}$ & $8 \mathrm{gm}^{-2}$ & \\
\hline & $4 \mathrm{gm}^{-2}$ & $14 \mathrm{~g} \mathrm{~m}^{-2}$ & $0 \mathrm{gm}^{-2}$ & $18 \mathrm{~g} \mathrm{~m}^{-2}$ & \\
\hline 1 & $10 \mathrm{~m}$ & \multicolumn{2}{|c|}{$40 \mathrm{~m}$} & & 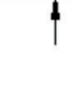 \\
\hline
\end{tabular}


node visible). This scale is the most used in wheat cultivation; it describes the external morphological states of the crop, which involve some development processes. Before planting, soil $\mathrm{N}$ was analyzed to determine the baseline level of this element in all the experimental units.

\section{Aerial image acquisition}

The aerial platform used was a UAV multirotor 3DR X8 + (3DRobotics, Berkeley, California, USA), the sensor used in this study was a modified Canon S110 near-infrared (NIR) digital camera (Event38 unmanned Systems, Akron, Ohio, USA), with blue, green, and NIR spectral bands (Figure 2).

Four flight missions were conducted during the middle stage of crop development. These missions were conducted during the Z45, Z55, Z61, and Z69 growth stages; these stages correspond to boots swollen, ear half emerged, beginning of anthesis, and anthesis completed, respectively. The missions were planned at $50 \mathrm{~m}$ above the ground level, with a frontal overlap of $70 \%$ and lateral overlap of $60 \%$. A spatial resolution with a pixel size of $1.5 \mathrm{~cm}$ was obtained.

\section{Field sampling}

A field sampling was conducted using the destructive method. The crop was cut as close to the soil surface as possible for an area of $0.25 \mathrm{~m}^{2}$, then it was weighed to determine the fresh matter. Later, the samples were dried in a stove and weighed to determine DM. Finally, the samples were milled, $50 \mathrm{~g}$ per sample were used for each experimental unit, and 28 samples per flight were sent to the agricultural laboratory to estimate $\mathrm{N}$ content (NC). This sampling process was completed for the four UAV flights.

\section{Image processing and experimental data}

Preprocessing was performed on the collected images; radiometric calibration was applied by using terrestrial targets with known reflectance. The process involved photographing the terrestrial targets at a height of approximately $2 \mathrm{~m}$, the digital numbers (DNs) were extracted from the pixels that covered the terrestrial targets in the image using FJ ImageJ software (US National Institutes of Health, Bethesda, Maryland, USA). A linear regression model was obtained using the DNs and the known reflectance reported by the target manufacturers. Finally, all the images were corrected using this linear model.

The images were processed using Pix4D software (Pix4D S.A., Prilly, Switzerland), ground control points were used to improve the precision of the generated orthomosaic map. We obtained a GeoTIFF format orthomosaic projected to the UTM coordinate system zone 14. The reflectance maps for the blue, green, and NIR spectral bands were obtained.

Biomass (DM) and NC data were subjected to a process of elimination of atypical values (outliers) using the interquartile range method, which is a statistical estimation of the dispersion of data distribution to prevent extreme values from affecting the average value of the variable of interest. Then, a graph of the behavior of the biomass and the NC over time (flight campaign dates) was created.

\section{Calculating vegetation indices}

One of the most commonly used indexes is the normalized difference vegetation index (NDVI), which contrasts the reflectance in the red (centered at $670 \mathrm{~nm}$ ) and the NIR (centered at $860 \mathrm{~nm}$ ) bands. However, this index saturates for LAI values greater than 3 . Due to this limitation, a series of alternative indices have been developed, including green NDVI (GNDVI), which is a variant of the NDVI where the red band is replaced by the green band, and blue NDVI (BNDVI), where the red band is replaced by the blue band. Table 1 shows the ratio of bands involved in the estimation of these indices and the source. Vegetation indices were estimated with Pix4D software (Pix4D S.A.)

Figure 2. Unmanned aerial vehicle (UAV) and digital camera (S110 NIR, Canon).
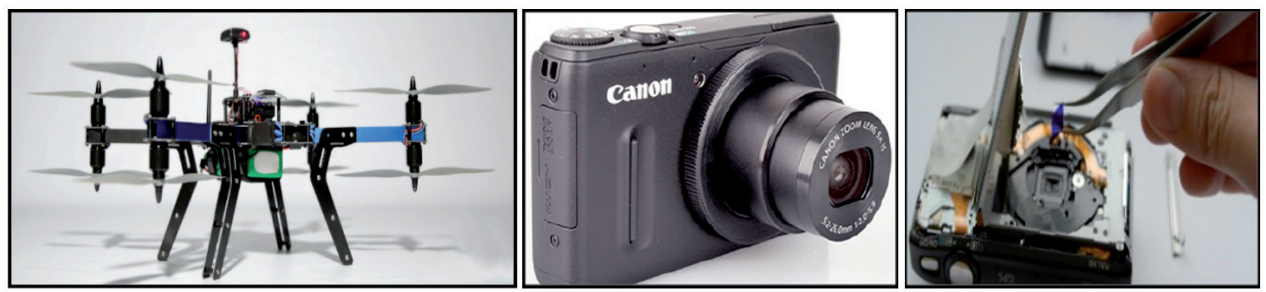
Table 1. Vegetation indices used in the study, equation, and sources.

\begin{tabular}{lll}
\hline Vegetation index & \multicolumn{1}{c}{ Equation } & \multicolumn{1}{c}{ Source } \\
\hline GNDVI & (NIR - GREEN)/(NIR + GREEN) & Gitelson et al., 1996 \\
BNDVI & (NIR - BLUE)/(NIR + BLUE) & Wang et al., 2007 \\
\hline
\end{tabular}

GNDVI: Green normalized difference vegetation index; BNDVI: blue normalized difference vegetation index; NIR: near-infrared band values; GREEN: green band values, BLUE: blue band values.

\section{Object-oriented classification}

Images were classified using the object-oriented classification technique to separate the vegetation (wheat) pixels from other classes, such as dried and wet soil, depending on the form, spatial, and spectral characteristics. Ecognition developer software (Trimble, Sunnyvale, California, USA) was used.

The object-oriented image analysis model is primarily based on segmenting the image, where segmentation characteristics are established to assign a greater weight (double) to the NIR band because this band more influences the detection of vegetation pixels, and the scale parameter of 20 was used, which depends on the size of the object in the image that was intended to be segmented. The criteria of homogeneity as the form and the compactness were 0.1 and 0.5 , respectively.

After the segmentation, classification was completed using supervised classification, which required training zones to define the different classes present in the image, and the nearest neighbor classifier was used.

\section{Extraction of the average value of the VI}

For each experimental unit, the VI statistics (mean, maximum, minimum, and standard deviation) were extracted with the Zonal Statistics tool in QGis software (OSGeo, Beaverton, Oregon, USA). The representative value of each unit was an average index value, which was used to correlate the wheat biomass and the NC parameters.

\section{Crop demand for $\mathbf{N}$}

The demand for $\mathrm{N}$ at any time in the crop cycle is defined as the result of the maximum crop mass and the critical concentration of $\mathrm{N}$ in the plant. The critical concentration of $\mathrm{N}$ in the plant is defined as the minimum concentration of $\mathrm{N}$ in the plant corresponding to the maximum crop mass (Greenwood et al., 1990). In this context, the demand corresponds to the minimum $\mathrm{N}$ absorption necessary to reach the maximum mass of a crop. This dynamic approach to crop $\mathrm{N}$ demand has been widely used in wheat crop (Schirrmann et al., 2016; Chen et al., 2019; Liu et al., 2020; Jiang et al., 2020).

\section{Critical $\mathbf{N}$ dilution curve}

The actual $\mathrm{N}$ concentration of the plant in a crop decreases, even when the supply of $\mathrm{N}$ is favorable, as the mass of the crop increases (Greenwood et al., 1986). This decrease is described empirically by a negative power function (Lemaire and Salette, 1984) that relates the $\mathrm{N}$ concentration of the plant $(\% \mathrm{~N})$ with the mass of the crop $\left(\mathrm{W}\right.$ in $\left.\mathrm{t} \mathrm{ha}^{-1}\right)$ during the period of vegetative growth (before anthesis):

$$
\% N=a \times W^{b}
$$

where a represents the $\mathrm{N}$ concentration of the plant for mass $\mathrm{W}=1 \mathrm{t} \mathrm{ha}^{-1}$. Its value depends on the level of supply of $\mathrm{N}$ in steady state and is also affected by the species considered. The element $\mathrm{b}$ is dimensionless and represents the relationship between the relative decrease in the plant $\% \mathrm{~N}$ and the relative growth rate of the crop.

When the supply of $\mathrm{N}$ is maintained at the minimum necessary to achieve the maximum growth rate of the crop throughout its growth period, then it is possible to define the critical $\mathrm{N}$ dilution curve $\left(\% \mathrm{~N}_{\mathrm{c}}\right)$ :

$$
\% N_{c}=a_{c} \times W^{-b}
$$

where $\mathrm{a}_{\mathrm{c}}$ is critical $\% \mathrm{~N}$ in the plant for a crop mass of $1 \mathrm{t} \mathrm{ha}{ }^{-1}$.

The tools that provide remote sensing are increasingly more common in the estimation of agronomic variables. In the particular case of the critical $\mathrm{N}$ dilution curve, instantaneous measurements of $\mathrm{N}$ content and biomass are necessary, which has led the scientific community to develop methodologies that can be easily, economically, and accurately used to estimate these variables.

In this research, the critical $\mathrm{N}$ dilution curve proposed by Justes et al. (1994) was used; these researchers reported the coefficients for a wheat crop as follows:

$$
\% N=5.35 \times W^{-0.442}
$$




\section{Diagnosis of $\mathbf{N}$ status in plants using the $\mathbf{N}$ nutrition index (NNI)}

To know the status of plant $\mathrm{N}$, it is necessary to use an index that indicates the situation of that element with respect to an optimal NC, so Lemaire and Gastal (1997) proposed the N nutrition index (NNI) to quantify N deficiency intensity or the excessive consumption with respect to the recommended $\mathrm{N}$ for a crop.

The concentration of plant $\mathrm{N}$ and the absorption of plant $\mathrm{N}$ should be interpreted in relation to the mass of the crop. The critical $\mathrm{N}$ dilution curve determined for each crop species allows for the separation of the actual $\mathrm{N}$ status of the crops in two situations: above the $\mathrm{N}$ critical curve, the crops excessively consume $\mathrm{N}$ compared to the recommended level to reach the maximum biomass; and below the critical curve, the crops have a deficient supply of $\mathrm{N}$.

Simultaneous measuring of $\mathrm{N}$ concentration of the plant and mass of the crop is necessary at any time during the vegetative growth period of the crop. The NNI is calculated as the relationship between the actual concentration of $\mathrm{N}$ $\left(\% \mathrm{~N}_{\mathrm{a}}\right)$ and the critical concentration of $\mathrm{N}$ in the plant $\left(\% \mathrm{~N}_{\mathrm{c}}\right)$ corresponding to the actual mass of the crop $\left(\mathrm{W}_{\mathrm{a}}\right)$ :

$$
N N I=\frac{\% N_{a}}{\% N_{c}}
$$

When NNI is about 1 , the $\mathrm{N}$ state of the plant is considered almost optimal. Deviations of 1 indicate deficiency $(\mathrm{NNI}<1$; deficiency intensity $=1-\mathrm{NNI})$ or excess $\mathrm{N}(\mathrm{NNI}>1$; excess intensity $=\mathrm{NNI}-1)$. Therefore, the determination of the $\mathrm{N}$ status of the plant in the objective stages of the growing period of the crop is a prerequisite for studying the response of the crop to excess or deficient $\mathrm{N}$. The NNI is used to calculate the instantaneous $\mathrm{N}$ status of the crop when the $\% \mathrm{~N}_{\mathrm{a}}$ of the plant and the actual crop biomass $\left(\mathrm{W}_{\mathrm{a}}\right)$ are determined. However, under a changing $\mathrm{N}$ supply in the field, it is necessary to determine the $\mathrm{N}$ status several times during the growing period of the crop.

Conventional or traditional methods to determine and characterize the nutritional status of crops refer to foliar analysis of total $\mathrm{N}$, whereas in situ sampling is used to estimate biomass. A reference frame with known dimensions is used, the aboveground plant material remaining within the framework is cut and dried to be weighed later, thus obtaining DM per unit of surface that later can be extrapolated into tons per hectare $\left(\mathrm{t} \mathrm{ha}^{-1}\right)$. These methods, in addition to being site specific are tedious and time-consuming.

\section{Data analysis}

The relationships between the VIs (BNDVI and GNDVI) and agronomic parameters (biomass and NC) were examined using the determination coefficient $\left(\mathrm{R}^{2}\right)$. The NNI estimation models were established using the best $\mathrm{R}^{2}$.

The discrepancy between NNI actual and NNI predicted with the UAV was estimated with the percent error equation:

$$
\% \text { Error }=\frac{\left|N N I_{\text {actual }}-N N I_{\text {predicted }}\right|}{N N I_{\text {actual }}} \times 100
$$

Other statistics used in this study to assess the model performance were the root mean square error (RMSE).

$$
R M S E=\sqrt{\frac{1}{N} \sum_{i=1}^{n}\left(N N I_{\text {predicted }}-N N I_{\text {actual }}\right)^{2}}
$$

The Nash and Sutcliffe model efficiency (NSE) was used to see how well the measured vs. estimated data fits:

$$
N S E=1-\frac{\sum_{i=1}^{n}\left(N N I_{\text {predicted }}-N N I_{\text {actual }}\right)^{2}}{\sum_{i=1}^{n}\left(N N I_{\text {actual }}-N N I_{\text {average }}\right)^{2}}
$$

where NNI average is the average of the measured values.

Percent bias (PBIAS) was also used; PBIAS measures the average tendency of the simulated data to be greater or lower than observed data:

$$
P B I A S=\left(\frac{\sum_{i=1}^{n}\left(N N I_{\text {actual }}-N N I_{\text {predicted }}\right)}{\sum_{i=1}^{n} N N I_{\text {actual }}}\right)
$$




\section{RESULTS AND DISCUSSION}

\section{Flight campaigns}

The results of the flight campaigns scheduled during the different phenological stages of the wheat cultivation are summarized in Table 2. The missions were conducted in the middle stage of the crop, corresponding to the stages of boots swollen (Z45), ear half emerged (Z55), beginning of anthesis (Z61), and end of anthesis (Z69). On average, 50 useful images were obtained by flight. During the 20 April flight, a problem occurred with the camera, so few photos were captured for that date. Despite this, we were able to rebuild the objects in the image. We obtained an average resolution of $1.5 \mathrm{~cm}$ per pixel, and the flight missions were executed around midday to avoid shading and the influence of the wind. Laliberte et al. (2010) performed flight tests up to 3:30 h prior to noon, due to the gusts of wind at their study site. As a result, images captured farther away from midday were more affected by shadows. To eliminate this component of shading, they used a hierarchical classification scheme, where they first differentiated shadows from what was not shadow, then used the nearest neighbor technique to identify the classes, reporting that with object-oriented techniques, it is possible to eliminate the shadow effect in the images to differentiate shadows from the vegetation.

\section{Aboveground biomass (dry weight)}

The biomass behaved with a positive linear trend: as flight dates advanced, dry weight of the collected samples increased. We observed that the rate of growth of the biomass was lower when the $\mathrm{N}$ treatment levels were low, whereas in high $\mathrm{N}$ dose treatments, the biomass increased more. The field data showed that the biomass is dependent on the dose of $\mathrm{N}$ applied. These results agree with data presented in previous investigations (Geipel et al., 2016; Melchiori et al., 2016). Figure 3 shows how biomass behavior was for the different $\mathrm{N}$ application levels for the four flight campaigns.

Table 2. Characteristics of flights made with unmanned aerial vehicle (UAV) at different phenological stages of wheat, identified using the Zadoks ( $Z$ ) scale, date of mission, number of images (n) captured with the sensor, flight height (A), ground control points (GCP), spatial resolution, and flight time.

\begin{tabular}{lcccccc}
\hline Date & $\mathrm{Z}$ & $\mathrm{n}$ & $\mathrm{A}(\mathrm{m})$ & GCP & $\begin{array}{c}\text { Resolution } \\
\text { (pixel size, } \mathrm{cm})\end{array}$ & Time \\
\hline 29 March 2017 & 45 & 46 & 50 & 8 & 1.50 & $12: 00$ \\
6 April 2017 & 55 & 57 & 50 & 8 & 1.59 & $11: 30$ \\
12 April 2017 & 61 & 55 & 50 & 8 & 1.51 & $13: 30$ \\
20 April 2017 & 69 & 33 & 50 & 8 & 1.39 & $12: 30$ \\
\hline
\end{tabular}

Z45: Boots swollen; Z55: ear half emerged; Z61: beginning of anthesis; Z69: anthesis completed.

Figure 3. Behavior of biomass (dry weight) for various levels of $\mathbf{N}$ application over time (four flight campaigns).

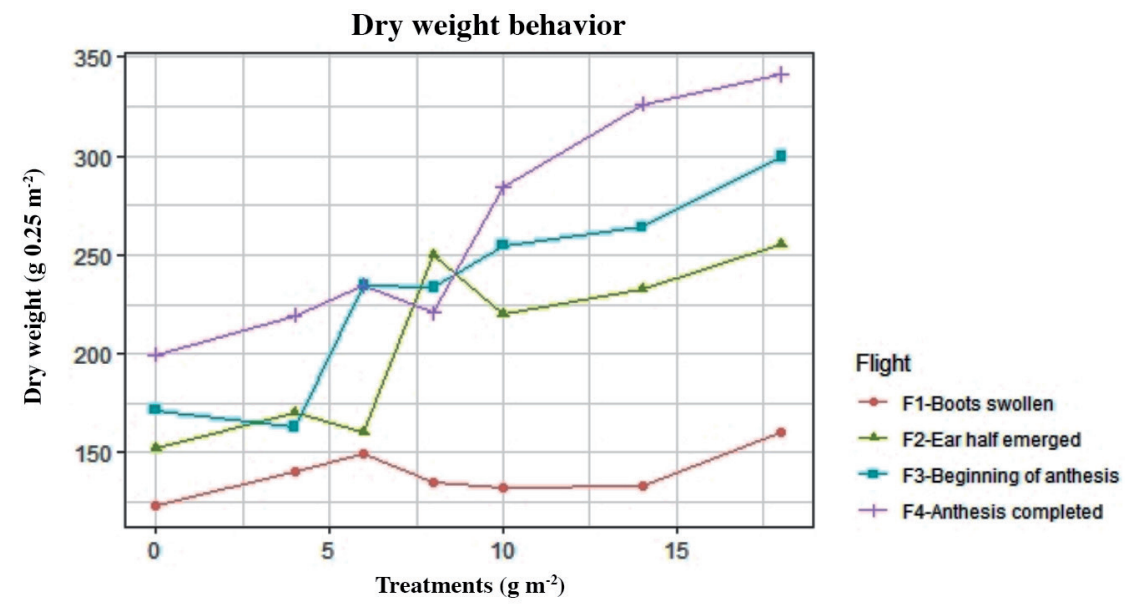




\section{Nitrogen content}

Laboratory results for the $\mathrm{NC}$ of the aerial part of the plant showed that as the flight time progressed, the NC decreased (Figure 4). This means that as the crop advances from middle life stages to the maturity, the NC decreases. The phenological stage of boots swollen, corresponding to the first flight, showed the highest values of NC, whereas the lowest values were observed at the end of anthesis, which corresponds to the last flight mission. Similarly, for flight 1 the slope of change was greater for the different treatments, whereas in flight 4, $\mathrm{NC}$ values in all treatments were practically horizontal.

The experiment showed a tendency for a higher percentage of $\mathrm{NC}$ with the increase of $\mathrm{N}$ dose, i.e., $\mathrm{N}$ application had an effect on the NC in wheat stem and straw. These findings agree with results reported for different cereals (Sure et al., 2006; Emam et al., 2009; Nikolic, 2009; Ballesteros et al., 2016).

In flight 3 (beginning of anthesis), we recorded an atypical decrease in the value of NC. When adjusting the trend line and estimating the $\mathrm{R}^{2}$, this value was not used because it was considered not representative compared to the other results.

\section{Correlation of vegetation indices with biophysical variables}

The results of the correlations between VIs and biophysical variables show a strong relationship. GNDVI and biomass (expressed as dry weight) during the flights 2 and 3 , showed the highest $\mathrm{R}^{2}(0.84$ and 0.79 , respectively; Figure 5). BNDVI and biomass demonstrated a high goodness of fit to flights 1 and $4\left(R^{2}=0.62\right.$ and $R^{2}=0.68$, respectively; Figure 5).

GNDVI index was the highest and lowest goodness of fit to biomass data with $\mathrm{R}^{2}$ ranging from 0.21 to 0.84 . The lower value could have been caused by the onset of senescence and therefore the yellowing of the plant. Prabhakara et al. (2015) mention that chlorosis may lead to inaccurate estimates of aboveground biomass when using vegetation indices to measure greenness of crops, regardless of species.

Figure 4. Behavior of $\mathbf{N}$ content for various levels of $\mathbf{N}$ application over time.

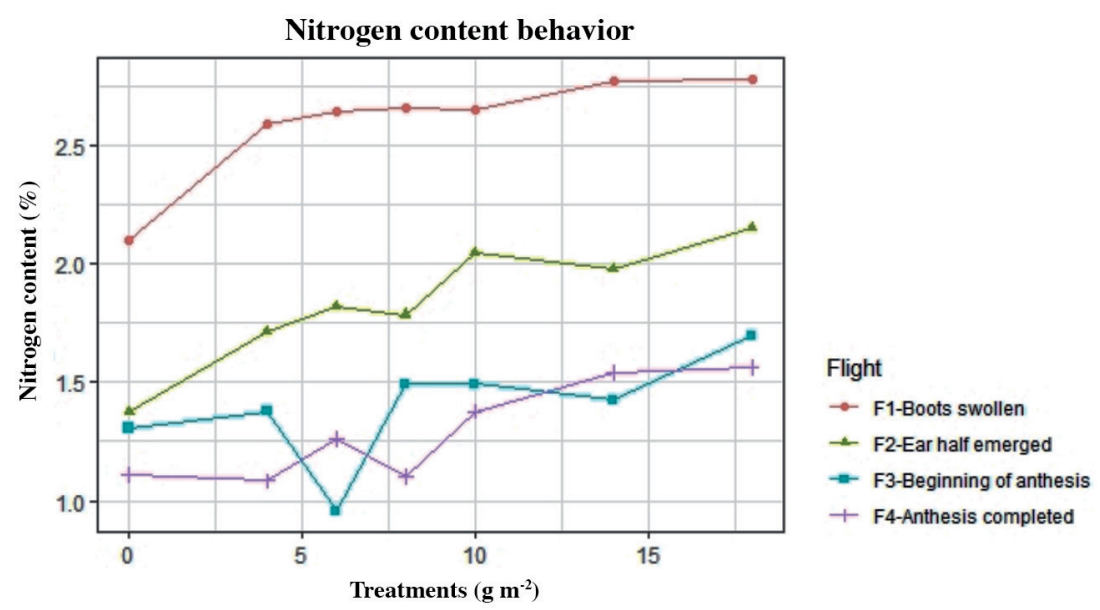

Figure 5. Relationship between vegetation index (GNDVI and BNDVI) and biomass for the four flights: F1 Boots swollen 29 March 2017, F2 ear half emerged 6 April 2017, F3 beginning of anthesis 12 April 2017, and F4 anthesis completed 20 April 2017.
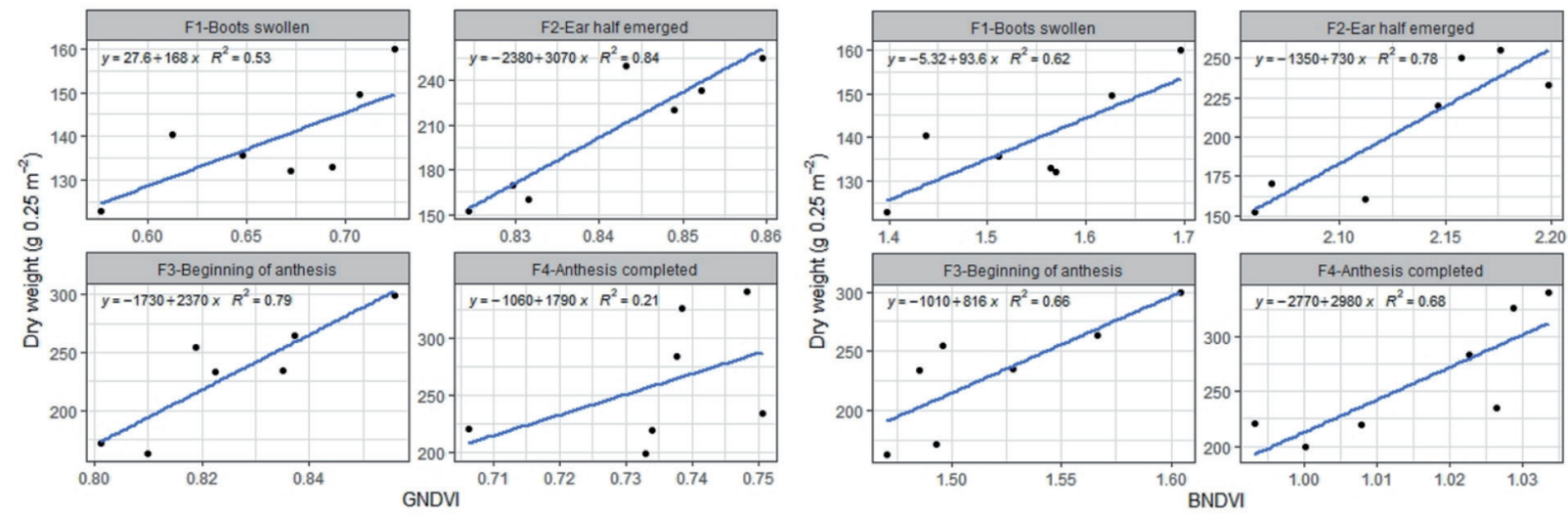

GNDVI: Green normalized difference vegetation index; BNDVI: blue normalized difference vegetation index. 
BNDVI presented more stable $\mathrm{R}^{2}$ values, ranging from 0.62 to 0.78 , three of the four flights presented very similar values. We observed that the greater the biomass, the greater the value of VIs for each flight. Hirzel et al. (2020) mentions that increasing $\mathrm{N}$ fertilization rate increases biomass and grain yield.

When analyzed together, it can be seen that after flight 2 the indices showed a decrease, despite the fact that the biomass continued to grow. Myneni and Williams (1994) mention that at higher biomass, especially in plants with planophile leaf structure, the sensitivity of the normalized difference vegetation index (NDVI) and other indices saturates as the canopy closes, and additional increases in biomass do not result in increased reflectance.

BNDVI and GNDVI showed a clear proportional relationship between the index and biomass up to ear half emerged stage.

Using vegetation indexes to identify differences in biomass in an agricultural field is viable since VIs differ during the growth of the crop, similar to the measured data in the field. These results are consistent with results reported previously by several studies (Wang et al., 2007; Campos et al., 2018).

The normalized difference vegetative indexes (NDVI) based on visible and near infrared reflectance (Vis-NIR NDVI) cannot differentiate the amount of biomass when there is too much vegetation, and Vis-NIR NDVI does appear to be a better predictor of biomass, specifically at earlier stages of growth (Moges et al., 2004; Gitelson, 2004; Bendig et al., 2015; Prabhakara et al., 2015; Zheng et al., 2019).

With regard to NC, the results show that the VIs during the four flight campaigns are linear (Figure 6). GNDVI was more highly correlated than BDVI, and the adjustment curve has an $\mathrm{R}^{2}$ up to 0.81 to GNDVI (Figure 6, F2), which is consistent with previous studies (Moges et al., 2004; Zhang et al., 2016; Zhao et al., 2018; Yang et al., 2020). The first three flight dates show a trend where the $0 \mathrm{~g} \mathrm{~m}^{-2}$ treatment had lower VIs values, and the $18 \mathrm{~g} \mathrm{~m}^{-2}$ treatment had higher VIs values, as expected. However, for the last flight date, the GNDVI values and NC showed less linearity and the $8 \mathrm{~g}$ $\mathrm{m}^{-2}$ treatment had a smaller GNDVI than the $0 \mathrm{~g} \mathrm{~m}^{-2}$ treatment, contrary to what was expected. This could be due to stress experienced by the crop, caused by other than NC.

After flight 2, the VIs began to decrease, which may correspond to the fact that they suffered saturation. In flight 2 the range of variation of the indices was very little.

Overall, the results presented in this research show that GNDVI is a good predictor of NC, providing a non-destructive alternative tool for monitoring NC. Other investigations reported similar results (Hatfield et al., 2008; Candiago et al., 2015; Magney et al., 2017).

Low levels of canopy cover may cause inaccuracies due to background reflectance of soils and crop residues interfering with the vegetation signal. The determination of pure vegetation pixels using the object-oriented classification technique helped to overcome the limitations caused by ground reflectance, shadows and other artifacts within the images.

Figure 6. Relationship between vegetation index (GNDVI and BNDVI) and N content (NC) for the four flights: F1 Boots swollen 29 March 2017, F2 ear half emerged 6 April 2017, F3 beginning of anthesis 12 April 2017, and F4 anthesis completed 20 April 2017.
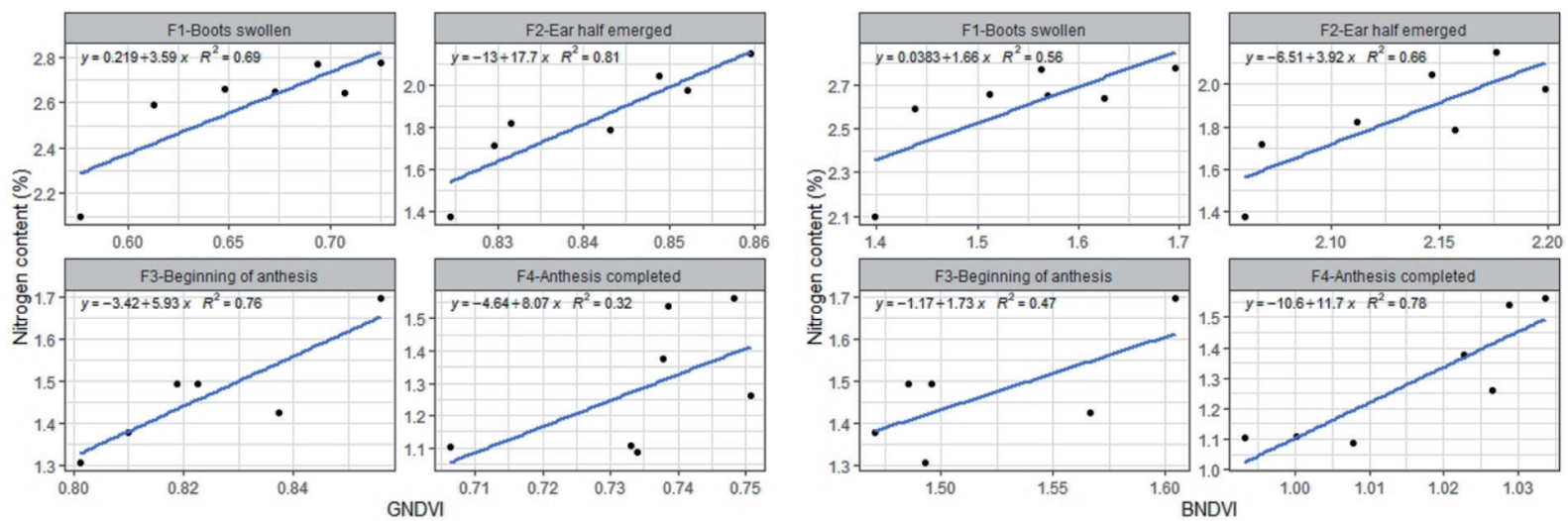

GNDVI: Green normalized difference vegetation index; BNDVI: blue normalized difference vegetation index. 
Figure 7 shows the variable crop response to the different rates of $\mathrm{N}$ application. It shows the capacity of the sensor to determine the spatial variability of the crop. Also, it is observed that the two vegetation indices (BNDVI and GNDVI) are sensitive to changes in the crop $\mathrm{N}$ content. In addition, this type of map is useful as it allows to the farmers, assimilate in an easier way, the crop status.

\section{Diagnosis of plant $\mathbf{N}$ status}

The critical $\mathrm{N}$ dilution curve refers to the minimum concentration of $\mathrm{N}$ that allows the crop to achieve its maximum growth rate. This curve was used to diagnose the wheat crop $\mathrm{N}$ status as optimal, in excess or in deficiency status.

Figure 8 shows the behavior of the actual $\mathrm{N}$ content to field data with respect to the dilution curve proposed by Justes et al. (1994) for all $\mathrm{N}$ treatments and the four flight campaigns. The $\mathrm{N}$ content remained relatively close to the proposed model. The $\mathrm{N}$ treatments used for flight 1 (boost swollen stage) were enough to maintain an optimal $\mathrm{NC}$ in the plants, except for the $0 \mathrm{~g} \mathrm{~m}^{-2}$ treatment. However, for the flight 2, only three treatments $\left(10,14\right.$, and $\left.18 \mathrm{~g} \mathrm{~m}^{-2}\right)$ were at or above the optimal $\mathrm{N}$ content. The rest of the treatments were insufficient to achieve an optimal plant $\mathrm{NC}$.

Obtained yields fluctuated from 4.7 to $6.4 \mathrm{t} \mathrm{ha}^{-1}$ corresponding to treatments from $0\left(0 \mathrm{~kg} \mathrm{ha}^{-1}\right)$ to $18 \mathrm{~g} \mathrm{~m}^{-2}\left(180 \mathrm{~kg} \mathrm{ha}^{-1}\right)$, which is consistent with results reported by Paquini et al. (2016) in a study carried out in the same region.

A high correlation was observed between measured and estimated data (Figure 9). A percent error of $6.17 \%$ was found between estimated and measured data. The UAV model was able to estimate the NNI with an acceptable accuracy. Regression statistics showed that the slope was close to the 1:1 line. Biomass and NC models showed that measured and estimated NNI matched satisfactorily with an $\mathrm{R}^{2}=0.91$, RMSE $=0.06, \mathrm{NSE}=0.91$, PBIAS $=-0.23 \%$.

The results reported here are consistent with those presented by Cilia et al. (2014) and Caturegli et al. (2016). This study show that the use of VIs derived from optical sensors and the NNI is a promising methodology to diagnose wheat $\mathrm{N}$ status.

Figure 7. Variability in vegetation indices responses to different $\mathrm{N}$ application rates: blue normalized difference vegetation index (BNDVI) (a) and green normalized difference vegetation index (GNDVI) (b).
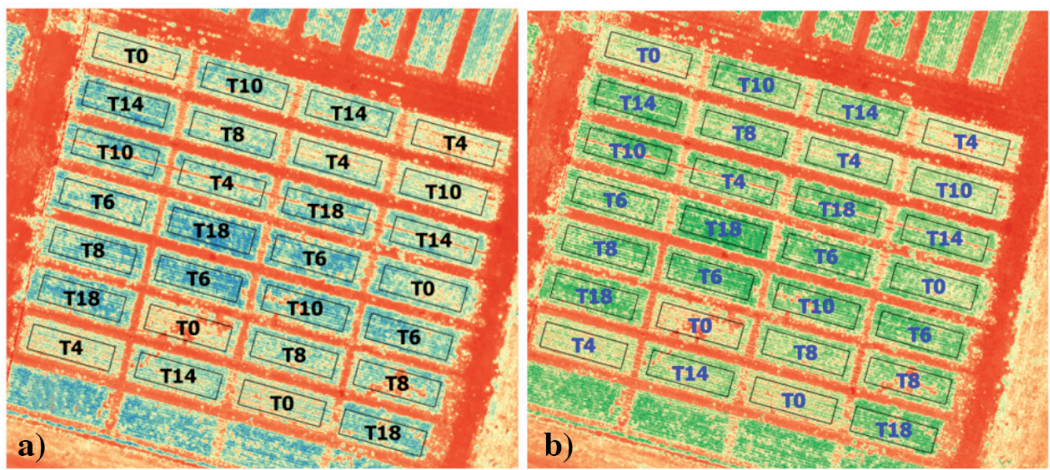

T0: $0 \mathrm{~g} \mathrm{~m}^{-2} ; \mathrm{T} 4: 4 \mathrm{~g} \mathrm{~m}^{-2} ; \mathrm{T} 6: 6 \mathrm{~g} \mathrm{~m}^{-2} ; \mathrm{T} 8: 8 \mathrm{~g} \mathrm{~m}^{-2} ; \mathrm{T} 10: 10 \mathrm{~g} \mathrm{~m}^{-2} ; \mathrm{T} 14: 14 \mathrm{~g} \mathrm{~m}^{-2} ; \mathrm{T} 18: 18 \mathrm{~g} \mathrm{~m}^{-2}$. 
Figure 8. Wheat $\mathbf{N}$ status for different used treatments compared to the critical $\mathbf{N}$ dilution curve (CNDC) proposed by Justes et al. (1994).

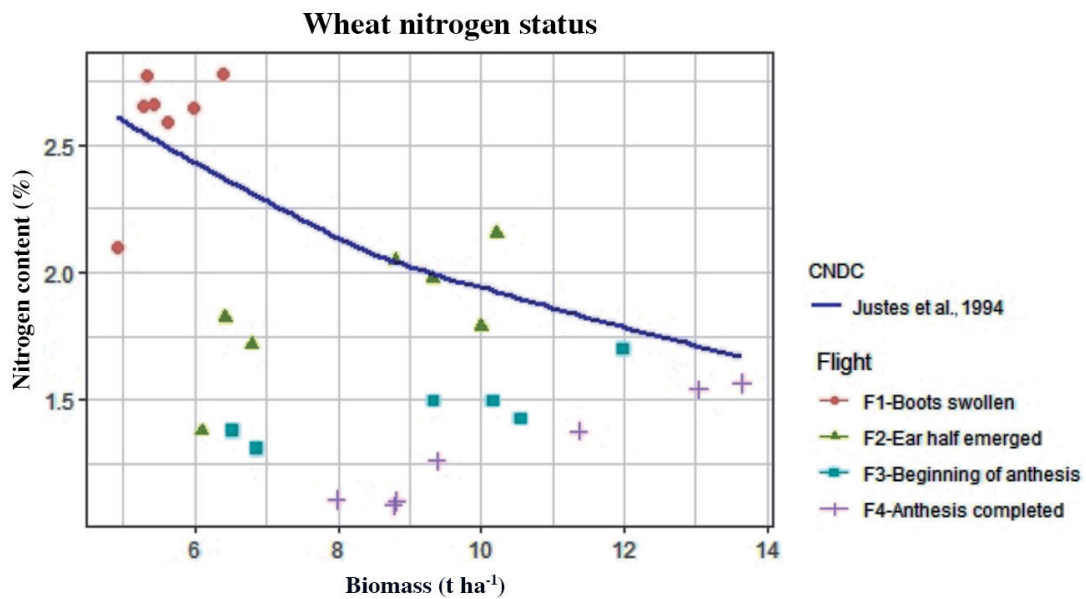

Figure 9. Field measure vs. unmanned aerial vehicles (UAV) estimated N nutrition index (NNI).

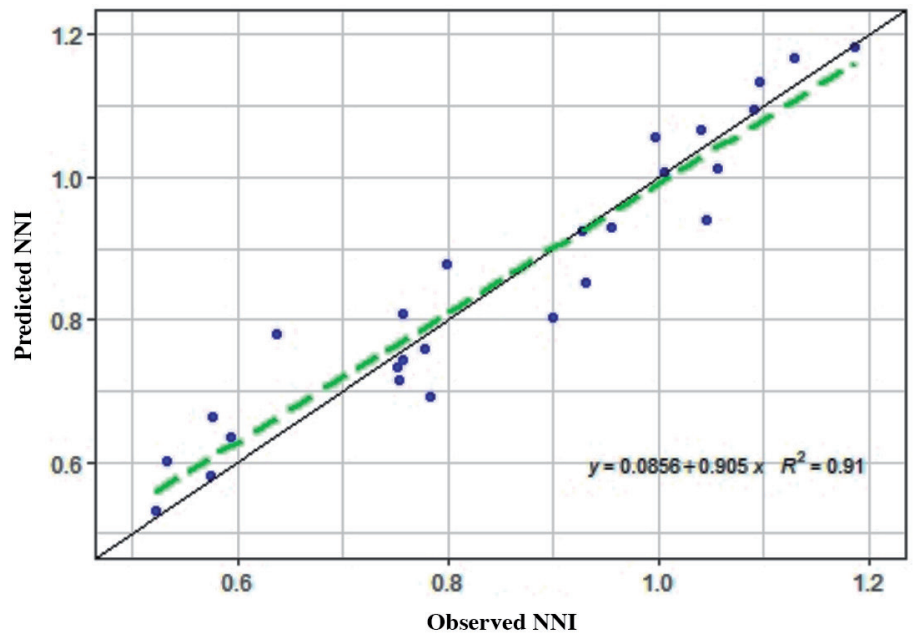

CONCLUSIONS

Vegetation indices (VIs) estimated from remote sensors mounted on unmanned aerial vehicles (UAVs) are useful to detect the wheat crop heterogeneous nutritional needs at the plot level. The VIs are sensitive to the changes that occur in the some phenological stages of a wheat crop. Green normalized difference vegetation index (GNDVI) showed great potential for biomass estimation and $\mathrm{N}$ content in wheat crop. GNDVI showed the highest determination coefficient during the ear half emerged stage.

In grow stages that experience the effects of index saturation at high biomass and leaf yellowing should be considered different VIs to ensure accuracy in estimating biomass and $\mathrm{N}$ content.

Also, it was found that a modified commercial camera, provide an economical and reliable option to monitor these wheat biophysical variables. UAVs are an affordable alternative for capturing high-resolution spectral and temporal images that permit to diagnose the wheat $\mathrm{N}$ status. 


\section{REFERENCES}

Ballesteros, E., Cow, G.V.M., Morales, R.E.J., Mora, F.O., Zamudio, G.B., and Gutiérrez, R.F.. 2016. Fractionation of nitrogen: Recovery efficiency and protein concentration in Triticale (xTriticosecale Wittmack). Revista Mexicana de Ciencias Agrícolas 7:585-598.

Bendig, J., Yua, K., Aasen, H., Bolten, A., Bennertz, S., Broscheit, J., et al. 2015. Combining UAV-based plant height from crop surface models, visible, and near infrared vegetation indices for biomass monitoring in barley. International Journal of Applied Earth Observation and Geoinformation 39:79-87.

Cameron, K., Di, H., and Moir, J. 2013. Nitrogen losses from the soil/plant system: A review. Annals of Applied Biology 162:145-173.

Campos, I., González, G.L., Carrilero, J., Calera, M., Campoy, J., Jiménez, N., et al. 2018. Mapping within-field variability in wheat yield and biomass using remote sensing vegetation indices. Precision Agriculture 20:214-236. doi:10.1007/s11119-018 -9596-Z.

Candiago, S., Remondino, F., De Giglio, M., Dubbini, M., and Gattelli, M. 2015. Evaluating multispectral images and vegetation indices for precision farming applications from UAV images. Remote Sensing 7:4026-4047. doi:10.3390/rs70404026.

Caturegli, L., Corniglia, M., Gaetani, M., Grossi, N., Magni, S., Migliazzi, M., et al. 2016. Unmanned aerial vehicle to estimate nitrogen status of turfgrasses. PLOS ONE 11:e0158268. doi:10.1371/journal.pone.0158268.

Chen, Z., Miao, Y., Lu, J., Zhou, L., Li, Y., Zhang, H., et al. 2019. In-season diagnosis of winter wheat nitrogen status in smallholder farmer fields across a village using unmanned aerial vehicle-based remote sensing. Agronomy 9(10):619. https://doi.org/10.3390/agronomy9100619.

Cilia, C., Panigada, C., Rossini, M., Meroni, M., Busetto, L., Amaducci, S., et al. 2014. Nitrogen status assessment for variable rate fertilization in maize through hyperspectral imagery. Remote Sensing 6:6549-6565. doi:10.3390/rs6076549.

Emam, Y., Salimi, K.S., and Shokoufa, A. 2009. Effect of nitrogen levels on grain yield and yield components of wheat (Triticum aestivum L.) under irrigation and rainfed conditions. Iranian Journal of Field Crops Research 7:323-334.

Geipel, J., Link, J., Wirwahn, J.A., and Claupein, W. 2016. A programmable aerial multispectral camera system for in-season crop biomass and nitrogen content estimation. Agriculture 6(1):4. doi:10.3390/agriculture6010004.

Gitelson,A.A. 2004. Wide dynamic range vegetation index for remote quantification of biophysical characteristics of vegetation. Journal of Plant Physiology 161(2):165-173.

Gitelson, A., Kaufman, J., and Merzlyak, N.M. 1996. Use of a green channel in remote sensing of global vegetation from EOSMODIS. Remote Sensing of Environment 58:289-298. doi:10.1016/S0034-4257(96)00072-7.

Greenwood, D.J., Lemaire, G., Gosse, G., Cruz, P., Draycott, A., and Neeteson, J.J. 1990. Decline in percentage N of C3 and C4 crops with increasing plant mass. Annals of Botany 66:425-436.

Greenwood, D.J., Neeteson, J.J., and Draycott, A. 1986. Quantitative relationships for the dependence of growth rate of arable crops on their nitrogen content, dry weight and aerial environment. Plant and Soil 91:281-301.

Hatfield, J.L., Gitelson, A.A., Schepers, J.S., and Walthall, C.L. 2008. Application of spectral remote sensing for agronomic decisions. Agronomy Journal 100:S-117-S-131. doi:10.2134/agronj2006.0370c.

Hirzel, J., Paredes, M., Becerra, V., and Donoso, G. 2020. Response of rice cropping with direct seeding to increasing rates of nitrogen, phosphorus, and potassium in two paddy rice soils. Chilean Journal of Agricultural Research 80:263-273.

Hunt, E.R., Jr., Hively, W.D., Fujikawa, S.J., Linden, D.S., Daughtry, C.S.T., and McCarty, G.W. 2010. Acquisition of NIR-green-blue digital photographs from unmanned aircraft for crop monitoring. Remote Sensing 2:290-305. doi:10.3390/rs2010290

Jiang, J., Wang, C., Wang, Y., Cao, Q., Tian, Y., Zhu, Y., et al. 2020. Using an active sensor to develop new critical nitrogen dilution curve for winter wheat. Sensors 20:1577. https://doi.org/10.3390/s20061577.

Justes, E., Mary, B., Meynard, J.M., Machet, J.M., and Thelier-Huche, L. 1994. Determination of a critical nitrogen dilution curve for winter wheat crops. Annals of Botany 74:397-407.

Laliberte, A.S., Herrick, J.E., Range, A.Y., and Winters, C. 2010. Acquisition, orthorectification, and object-based classification of unmanned aerial vehicle (UAV) imagery for rangeland monitoring. Photogrammetric Engineering \& Remote Sensing 76:661-672.

Lemaire, G., and Gastal, F. 1997. N uptake and distribution in plant canopies. p. 3-43. In Lemaire, G. (ed.) Diagnosis of the nitrogen status in crops. Springer, Heidelberg, Germany.

Lemaire, G., et Salette, J. 1984. Relation entre dynamique de croissance et dynamique de prélèvement d'azote pour un peuplement de graminées fourragères. I. Etude de l'effet du milieu. Agronomie 4:423-430.

Liu, H., Zhu, H., Li, Z., and Yang, G. 2020. Quantitative analysis and hyperspectral remote sensing of the nitrogen nutrition index in winter wheat. International Journal of Remote Sensing 41(3):858-881. doi:10.1080/01431161.2019.1650984.

Magney, T.S., Vain, J.U.H., and Vierling, L.A. 2017. Mapping wheat nitrogen uptake from RapidEye vegetation indexes. Precision Agriculture 18:429-451. doi:10.1007/s11119-016-9463-8. 
Melchiori, R.J.M., Kemerer, A.C., Casuccio, L.M., y Albarenque, S.M. 2016. Uso de imágenes de drones y sensores para evaluar el efecto del nitrógeno en trigo. In $15^{\circ}$ Curso internacional de agricultura y ganadería de precisión con agregado de valor en origen, Córdoba. 28-29 Septiembre. Instituto Nacional de Tecnología Agropecuaria, Estación Experimental Agropecuaria Manfredi, Córdoba, Argentina.

Moges, S.M., Raun, W.R., Mullen, R.W., Freeman, K.W., Johnson, G.V., and Solie, J.B. 2004. Evaluation of green, red and near infrared bands for predicting winter wheat biomass, nitrogen uptake, and final grain yield. Journal of Plant Nutrition 27(8):1431-1441.

Myneni, R.B., and Williams, D.L. 1994. On the relationship between FAPAR and NDVI. Remote Sensing of Environment 49:200-211.

Nikolic, O. 2009. Geneticka Divergentnost Genotipova Psenice za parameter efikasnosti ishrane azotom. 112 p. PhD Thesis. Faculty of Agriculture Zemun, Belgrade, Serbia.

Paquini, R.S.L., Benítez, R.I., Villaseñor, M.H.E., Muñoz, O.A., y Vaquera, H.H. 2016. Incremento en el rendimiento y sus componentes bajo riego normal y restringido de variedades mexicanas de trigo. Revista Fitotecnia Mexicana 39(4):367-378.

Prabhakara, K., Hively, W.D., and McCarty, G.W. 2015. Evaluating the relationship between biomass, percent groundcover and remote sensing indices across six winter cover crop fields in Maryland, United States. International Journal of Applied Earth Observation and Geoinformation 39:88-102. https://doi.org/10.1016/j.jag.2015.03.002.

Schirrmann, M., Giebel, A., Gleiniger, F., Pflanz, M., Lentschke, J., and Dammer, K.-H. 2016. Monitoring agronomic parameters of winter wheat crops with low-cost UAV imagery. Remote Sensing 8(9):706. https://doi.org/10.3390/rs8090706.

Spiertz, J.H.J. 2010. Nitrogen, sustainable agriculture, and food security. A review. Agronomy for Sustainable Development $30: 43-55$

Sure, S.O., Wilson, L.T., Medley, J.C., Finch, S.R.M., McClung, A.M., and Lales, J.S. 2006. Nitrogen utilization efficiency: Relationships with grain yield, grain protein, and yield-related traits in rice. Agronomy Journal 98:168-176.

Wang, F.M., Huang, J.F., Tang, Y.L., and Wang, X.Z. 2007. New vegetation index and its application in estimating leaf area index of rice. Rice Science 14(3):195-203.

Yang, M., Hassan, M.A., Xu, K., Zheng, C., Rasheed, A., Zhang, Y., et al. 2020. Assessment of water and nitrogen use efficiencies through UAV-based multispectral phenotyping in winter wheat. Frontiers in Plant Science 11:927. doi:10.3389/fpls.2020.00927.

Zhang, Y., Su, Z., Shen, W., Jia, R., and Luan, J. 2016. Remote monitoring of heading rice growing and nitrogen content based on UAV images. International Journal of Smart Home 10:103-114. http://dx.doi.org/10.14257/ijsh.2016.10.7.11.

Zhao, B., Duan, A., Ata-Ul-Karim, S.T., Liu, Z., Chen, Z., Gong, Z., et al. 2018. Exploring new spectral bands and vegetation indices for estimating nitrogen nutrition index of summer maize. European Journal of Agronomy 93:113-125.

Zheng, H., Cheng, T., Zhou, M., Li, D., Yao, X., Tian, Y., et al. 2019. Improved estimation of rice aboveground biomass combining textural and spectral analysis of UAV imagery. Precision Agriculture 20:611-629. https://doi.org/10.1007/s11119-018-9600-7. 